\title{
Tanshinone IIA pretreatment protects free flaps against hypoxic injury by upregulating stem cell-related biomarkers in epithelial skin cells
}

Zihan $\mathrm{Xu}^{1+}$, Lijun $\mathrm{Wu}^{2+}$, Yaowen Sun ${ }^{1}$, Yadong Guo ${ }^{1}$, Gaoping Qin', Shengzhi Mu', Ronghui Fan ${ }^{1}$, Benfeng Wang ${ }^{1}$, Wenjie Gao ${ }^{1}$ and Zhenxin Zhang ${ }^{1 *}$

\begin{abstract}
Background: Partial or total flap necrosis after flap transplantation is sometimes encountered in reconstructive surgery, often as a result of a period of hypoxia that exceeds the tolerance of the flap tissue. The purpose of this study was to determine whether Tanshinone IIA (TSA) pretreatment can protect flap tissue against hypoxic injury and improve its viability.

Methods: Primary epithelial cells isolated from the dorsal skin of mice were pretreated with TSA for 2 weeks. Cell Counting Kit-8 and Trypan Blue assays were carried out to examine the proliferation of TSA-pretreated cells after exposure to cobalt chloride. Polymerase chain reaction and western blot analysis were used to assess the expression of $\beta$-catenin, vascular endothelial growth factor (VEGF), sex determining region Y-box 2 (SOX2), OCT4 (also known as POU domain class 5 transcription factor 1), Nanog, and glycogen synthase kinase-3 beta (GSK-3ß) in TSA-treated cells. In other experiments, after mice were pretreated with TSA for 2 weeks, a reproducible ischemic flap model was implemented, and the area of surviving tissue in the transplanted flaps was measured. Immunohistochemistry was conducted to examine Wnt signaling as well as stem cell- and angiogenesis-related biomarkers in epithelial tissue in vivo.
\end{abstract}

Results: Epidermal cells, pretreated with TSA, showed enhanced resistance to hypoxia. Activation of the Wnt signaling pathway in TSA-pretreated cells was characterized by the upregulation of $\beta$-catenin and the downregulation of GSK-3 $\beta$. The expression of SOX2, Nanog, and OCT4 were also higher in TSA-pretreated epithelial cells than in control cells. In the reproducible ischemic flap model, pretreatment with TSA enhanced resistance to hypoxia and increased the area of surviving tissue in transplanted flaps. The expression of Wnt signaling pathway components, stem-cell related biomarkers, and VEGF and CD34, which are involved in the regeneration of blood vessels, was also upregulated in TSA-pretreated flap tissue.

Conclusions: TSA pretreatment protects free flaps against hypoxic injury and increases the area of surviving tissue by activating Wnt signaling and upregulating stem cell-related biomarkers.

Keywords: Free flap, Epithelial cell, Traditional Chinese medicine, Wnt, Stem cell

\section{Background}

Flaps are routinely used in plastic surgery for covering tissue defects resulting from trauma, ablative surgery, or congenital malformation, although partial or total flap necrosis after flap surgery is not uncommon [1,2]. The transplantation of marrow mesenchymal cells [3] and

\footnotetext{
*Correspondence: zzsxa2006@126.com

${ }^{\dagger}$ Equal contributors

'Department of Burns and Plastic Surgery, Shaanxi Provincial People's

Hospital, 256 West Youyi Road, Xi'an 710068, China

Full list of author information is available at the end of the article
}

adipose-derived stem cells [4] is effective in regenerating tissue, and Yi et al. [5] report that vascular endothelial growth factor (VEGF) gene therapy can enhance the survival and quality of grafted fat tissue in nude mice. It is also reported that hyperbaric $\mathrm{O}_{2}$ is clinically effective as an adjuvant therapy for improving wound healing and neovascularization and attenuating oxidative stress [6]. At the same time, however, there are still clear potential disadvantages of these treatment strategies. Considering hyperbaric $\mathrm{O}_{2}$, there is a risk for $\mathrm{O}_{2}$ toxicity [7], 
progressive myopia [8], and grand mal seizures [8] after treatment. Furthermore, more research is needed into stem cell transplantation and gene therapy before experimental results can be translated into broad clinical application $[9,10]$. As flap transplantation is becoming more widely used in reconstructive surgery, it is important to understand the mechanism of flap necrosis so that it can be prevented.

Ischemia occurs when there is inadequate blood flow to a specific tissue area after flap reconstruction, and it is an underlying cause of tissue hypoxia and flap loss [11]. When hypoxia exceeds the tolerance level of epithelial cells, necrosis or scarring of flap tissue occurs. Although not all epithelial skin cells exhibit the same resilience to hypoxia, they are a promising source of stem cells that are resistant to noxious surroundings, exhibit anti-apoptotic characteristics, and possess enhanced DNA repair machinery, which are essential properties for cell regeneration and repair [12]. Stem cells are defined by their capacity for self-renewal and their resistance to maladaptive microenvironments, including hypoxia, and there is now compelling evidence that multipotent stem cells contribute to recovery from hypoxia and epidermal repair $[13,14]$.

Recent advances in our understanding of epithelial stem cells, together with explorations of stem cell-related signaling pathways that control the regeneration of skin, open a new door for improvements in flap surgery. Wht signaling, which is required for tissue repair and regeneration, is involved in the growth of various cell types and plays a critical role in stem cell maintenance and differentiation $[15,16]$. SOX2, Nanog, and OCT4, which are regulated by Wnt signaling, are markers of somatic cell stemness [17]. Takahashi et al. [18] induced pluripotent stem cells by transducing adult human dermal fibroblasts with defined factors such as OCT4 and SOX2. When Wnt signaling is reduced, its associated biomarkers, such as OCT4, SOX2, and $\beta$-catenin, are downregulated, and cell resistance to hypoxia and capacity for regeneration are also impaired [19,20]. For instance, in the zebrafish eye, the inhibition of Wnt signaling results in an abrupt cessation of the normally continuous regeneration of the retina [21]. Also, inhibition of Wnt signaling during skin wounding in mice prevents the formation of epithelial appendages, including hair and sweat glands, which results in prominent scarring of the epidermis [22]. By contrast, elevating Wnt signaling within the wound site promotes the growth of adult skin [22]. Several studies also show that increasing Wnt signaling stimulates healing of many different injuries, including bone fractures, retinal damage, skin wounding, and myocardial infarction [23]. If Wnt signaling is required for tissue regeneration, can we find a convenient and effective way to elevate Wnt signaling in epithelial skin cells with limited regenerative capacity to improve the healing response?
Tanshinone IIA (TSA) is the most abundant diterpene quinone isolated from Danshen (Salvia miltiorrhiza) and has been used to treat cardiovascular diseases for more than 2000 years in China. Over the last decade, interest in the mechanism of its versatile protective effects in neurodegenerative diseases, metabolic abnormalities, and ischemic damage has been growing [24-30]. For instance, Zhang et al. demonstrated that TSA enhances cell resistance to hypoxic insult by upregulating miR-133 expression through activation of the mitogen-activated protein kinase (MAPK)/extracellular signal-related kinase (ERK) pathway in neonatal cardiomyocytes [31]. Chen et al. showed that TSA has neuroprotective effects against ischemia/reperfusion (I/R) injury through the inhibition of macrophage migration inhibitory factor (MIF) and the release of tumor necrosis factor- $\alpha$ and interleukin- 6 in rats [24]. Furthermore, Zhu et al. found that TSA protects rat primary hepatocytes against carbon tetrachloride toxicity via inhibiting mitochondria permeability transition [32].

In the present study, we investigated whether TSA could protect free flaps against hypoxia-induced necrosis and improve tissue viability in the hypoxic zone. Next, we examined the regulation of the Wnt signaling pathway and stem cell-related biomarkers in epithelial cells and tissue. Finally, we tested whether TSA therapy activates the Wnt signaling pathway and upregulates stem cell-related biomarkers in epithelial cells.

\section{Methods}

\section{Regents and antibodies}

TSA injection (sulfotanshinone sodium injection, $5 \mathrm{mg} / \mathrm{mL}$; First Biochemical Pharmaceutical Co. Ltd., Shanghai, China) was used in the in vivo experiments. TSA monomer (Sigma, St. Louis, MO), a lyophilized powder (99.99\% purity), which was first dissolved in dimethyl sulfoxide, and then diluted with phosphate-buffered saline (PBS) to the required concentration, was used in the in vitro experiments. Antibodies used for immunoblotting and/or immunohistochemistry were as follows: mouse anti-human monoclonal $\beta$-catenin (Abcam, Cambridge, MA, USA), rabbit anti-human polyclonal glycogen synthase kinase-3 beta (GSK-3ß; Epitomics, Burlingame, CA, USA), rabbit anti-human polyclonal SOX2 (Epitomics, Burlingame, CA, USA), mouse anti-human monoclonal OCT4 (Abcam, Cambridge, MA, USA), mouse anti-human monoclonal Nanog (Abcam, Cambridge, MA, USA), rabbit anti-human polyclonal VEGF (Abcam, Cambridge, MA, USA), mouse anti-human monoclonal CD34 (Abcam, Cambridge, MA, USA), and mouse antihuman monoclonal actin (Beyotime, Shanghai, China).

\section{Isolation and preparation of epidermal cells}

To obtain epithelial cells of high purity, the dorsal skin of male BALB/C mice was processed as previously described with slight modifications [33]. Immediately after 
mice were killed by cervical dislocation, the shaved dorsal skin was treated for $5 \mathrm{~min}$ with a depilatory agent, rinsed under running water, excised, and placed in icecold Dulbecco's Modified Eagle's Medium (DMEM). The subcutis was removed by scraping with a razor blade. The skin, consisting of dermis and epidermis, was minced with scissors, and the pieces were washed once with DMEM. The pieces of skin were excised and cut into smaller pieces in collagenase buffer containing $0.05 \%$ collagenase IV and $0.25 \%$ trypsin for $2 \mathrm{~h}$. The digestion solution was filtered through nylon gauze, and the filtrate was sedimented twice by centrifugation at $70 \times \mathrm{g}$ for $5 \mathrm{~min}$ at $4^{\circ} \mathrm{C}$. Finally, cells were collected, counted, and resuspended with DMEM containing $10 \%$ fetal bovine serum at a concentration of $5 \times 10^{5}$ in $\mathrm{T}_{25}$ flasks. Two days later, cells were digested with $0.25 \%$ trypsin and washed gently with PBS to remove fibroblasts resulting from the strong adhesion of epithelial cells. Finally, cells were digested and passaged by repeating the above steps three times to obtain epithelial cells with high purity.

\section{Cell proliferation assay}

Primary epithelial cells were pretreated with TSA $(2 \mathrm{mg} / \mathrm{L}$, $\mathrm{IC}_{50} 98 \mathrm{mg} / \mathrm{L}$, without pro-proliferative effect) for 2 weeks and transferred to glass cover slips and grown to 50\% confluence. Cells were exposed to cobalt chloride $\left(\mathrm{CoCl}_{2}\right.$ $50 \mu \mathrm{mol} / \mathrm{L}$ ) in vitro for $72 \mathrm{~h}$ to mimic hypoxia, fixed, permeabilized, and stained with 4'-6-diamidino-2-phenylindole (DAPI) to visualize cell nuclei using fluorescence microscopy (Olympus, Tokyo, Japan).

Other primary epithelial cells were pretreated with TSA ( $2 \mathrm{mg} / \mathrm{L}$ ) for 2 weeks, and then exposed to $\mathrm{CoCl}_{2}$ $(50 \mu \mathrm{mol} / \mathrm{L})$ in vitro for $24,48,72$, or $96 \mathrm{~h}$. Cell proliferation was assessed using the Cell Counting Kit-8 (CCK8; Dojindo Molecular technologies, inc, Japan). Results are expressed as the absorbance of each well at $450 \mathrm{~nm}$ (OD450). The half maximal inhibitory concentration $\left(\mathrm{IC}_{50}\right)$ of $\mathrm{CoCl}_{2}$ was $179 \mu \mathrm{mol} / \mathrm{L}$ for a $72 \mathrm{~h}$ treatment time (data not shown). Almost half of the primary epithelial cells died and floated in the culture flasks at this concentration. After several preliminary experiments, a concentration of $50 \mu \mathrm{mol} / \mathrm{L}$, which is far below the $\mathrm{IC}_{50}$, was selected to mimic hypoxia.

\section{Trypan blue assay}

Primary epithelial cells were pretreated with TSA for 2 weeks and exposed to $\mathrm{CoCl}_{2}(50 \mu \mathrm{mol} / \mathrm{L})$ for $72 \mathrm{~h}$. Cells were digested and suspended in PBS. Cell suspension solution $(0.5 \mathrm{ml})$ and $0.4 \%$ Trypan Blue solution $(0.5 \mathrm{ml})$ were added to a test tube and mixed thoroughly for 5 min to stain non-viable cells blue. Separate counting of viable and non-viable cells was performed, and cell viability (\%) was calculated as (viable cells / (viable cells + non-viable cells)) $\times 100 \%$.
Quantitative real-time polymerase chain reaction (qRT-PCR) Total RNA was extracted from TSA-treated primary epithelial cells and their parental cell lines using Trizol Reagent (Invitrogen, Grand Island, NY, USA). Total RNA was reversely transcribed using a Prime Script RT Reagent Kit (TaKaRa, Biotechnology, inc, Dalian, China). mRNA expression was determined by qRT-PCR using SYBR Premix Ex Taq II (TaKaRa). The primers used for the amplification of target genes were as follows:

$\beta$-catenin forward primer 5'ATGGCTACTCAAGCT GAC-3' and reverse primer 5'-CAGCACTTTCAGCAC TCTGC-3';

GSK-3 $\beta$ forward primer 5'-GTTGGTGGAAATAATA AAGG-3' and reverse primer 5'-AAGTTGAAGAGGGC AGGT-3';

SOX2 forward primer 5'-GTGGTGGTACGGGAAAT CAC-3' and reverse primer 5'-TAGCCAGGTTCGAGA ATCCA-3';

OCT4 forward primer 5'-CTGGGTTGATCCTCGGA CCT-3' and reverse primer 5'-CACAGAACTCATACG GCGGG-3';

Nanog forward primer 5'-AAAGAATCTTCACCTAT GCC-3' and reverse primer 5'-GAAGGAAGAGGAGAG ACAGT-3';

VEGF forward primer 5'-TTACTGCTGTACCTCCA CC-3' and reverse primer 5'-ACAGGACGGCTTGAA GATG-3'; and

$\beta$-actin forward primer 5'-CAATGTGGCCGAGGAC TTTG-3' and reverse primer 5'-CATTCTCCTTAGAG AGAAGTGG-3'.

\section{Western blot analysis}

Expression of $\beta$-catenin, SOX2, OCT4, Nanog, VEGF, and actin in control and TSA-Treated epithelial cells was detected by western blot analysis as previously described with slight modifications [34]. To prepare whole-cell protein extracts, cells were washed twice with phosphatebuffered saline and then lysed with a modified radioimmunoprecipitation assay buffer $(50 \mathrm{mM}$ Tris- $\mathrm{HCl}$ $\mathrm{pH} 7.4,1 \% \mathrm{v} / \mathrm{v}$ NP-40, $0.25 \%$ v/v sodium deoxycholate, $150 \mathrm{mM} \mathrm{NaCl}, 1 \mathrm{mM}$ EDTA, $1 \mathrm{mM}$ PMSF, $1 \mathrm{mg} / \mathrm{mL}$ of protease inhibitors (leupeptin and pepstatin), $1 \mathrm{mM}$ $\mathrm{Na}_{3} \mathrm{VO}_{4}$, and $1 \mathrm{mM} \mathrm{NaF}$ ) on ice for $30 \mathrm{~min}$. Insoluble material was removed by centrifugation at $12,000 \mathrm{p} / \mathrm{min}$ for $15 \mathrm{~min}$ at $4^{\circ} \mathrm{C}$. The protein concentration of cell lysates was measured using the Bradford Protein Assay Kit (Beyotime, Shanghai, China), and $30 \mu \mathrm{g}$ of protein samples were loaded on $10 \%$ polyacrylamide gels containing sodium dodecyl sulfate and separated by electrophoresis at a constant voltage of $70 \mathrm{~V}$ for $2 \mathrm{~h}$ and transferred onto $0.45-\mu \mathrm{m}$ polyvinylidene fluoride membranes (Millipore Corporation, Billerica, MA, USA) at a constant voltage of $100 \mathrm{~V}$ for $3 \mathrm{~h}$ at $0^{\circ} \mathrm{C}$. The membranes were probed with the specific primary antibodies followed 
by a horseradish peroxidase-conjugate secondary antibody $(1: 5,000)$ and detected by enhanced chemiluminescence (ECL kit from Pierce, Rockford, IL, USA). The following primary antibodies were used: $\beta$-catenin (dilution 1:1000), SOX2 (dilution 1:400), OCT4 (dilution 1:400), Nanog (dilution 1:500), VEGF (dilution 1:1000), and actin (dilution 1:1000). Unless otherwise indicated, immunoblot reagents were purchased from Beyotime.

\section{Animals and ethics statement}

BALB/c mice (aged 4-6 weeks and weighing approximately $20 \mathrm{~g}$ ) were obtained from the Chinese Academy of Science and maintained under standard pathogen-free conditions. The experimental protocol was approved by the Shanghai Medical Experimental Animal Care Commission. All surgery was performed under sodium pentobarbital anesthesia, and all efforts were made to minimize suffering.

\section{In vivo evaluation of free flap survival}

$\mathrm{BALB} / \mathrm{c}$ mice were randomly assigned to the TSA group $(n=6)$ or the control group $(n=6)$. TSA mice were injected intraperitoneally with $0.1 \mathrm{ml} \mathrm{TSA}(10 \mathrm{mg} / \mathrm{kg} / \mathrm{d})$ diluted in $5 \%$ glucose solution (5\% GS) for 14 days. Control mice were injected with $0.1 \mathrm{ml} 5 \%$ GS. The reproducible ischemic flap model (Figure 1) was implemented as previously described with slight modifications [35]. The dorsal skin area of $\mathrm{BALB} / \mathrm{c}$ mice was depilated and cleaned, and dorsal random-pattern flaps measuring $1 \times 3 \mathrm{~cm}$ were constructed. After the flap was elevated, $1 \times 0.2 \mathrm{~cm}$ epithelial skin tissues in the distal end of the flap were excised for immunohistochemistry, and the main vessels in the flap were coagulated by cautery. Finally, the flap was repositioned and sutured. The percentage of flap survival area was calculated with standard grid paper 7 days after surgery.

\section{Immunohistochemistry}

Immunohistochemical staining of $\beta$-catenin, GSK-3 $\beta$, SOX2, OCT4, VEGF, and CD34 was carried out using a standard protocol with slight modifications [36]. Epithelial skin tissue was fixed, embedded, and sliced into 5 - $\mu \mathrm{m} \mathrm{sec-}$ tions. Then, the sections were permeabilized, blocked, and incubated with primary monoclonal antibodies overnight at $4^{\circ} \mathrm{C}$. Sections were washed and incubated with antimouse or anti-rabbit HRP conjugated secondary antibody (Jackson). Finally, the sections were counterstained with hematoxylin, dehydrated, and cleared with xylene before finally being mounted. The following primary antibodies were used: $\beta$-catenin (dilution 1:500), SOX2 (dilution 1:150), OCT4 (dilution 1:200), VEGF (dilution 1:1000), and CD34 (dilution 1:500).

\section{Statistical analysis}

Data are expressed as mean \pm standard error of the mean (SEM). Student's t-tests were used to compare groups. Statistical analysis was performed using SPSS 17.0 software for Windows (SPSS Inc. Chicago, IL, USA). P $<0.05$ was considered statistically significant.

\section{Results}

Epithelial skin cells showed enhanced resistance to hypoxia after TSA pretreatment

DAPI staining showed that isolated epithelial skin cells that were pretreated with TSA $(2 \mathrm{mg} / \mathrm{L})$ for 2 weeks exhibited enhanced resistance to $\mathrm{CoCl}_{2}$. That is, the viability

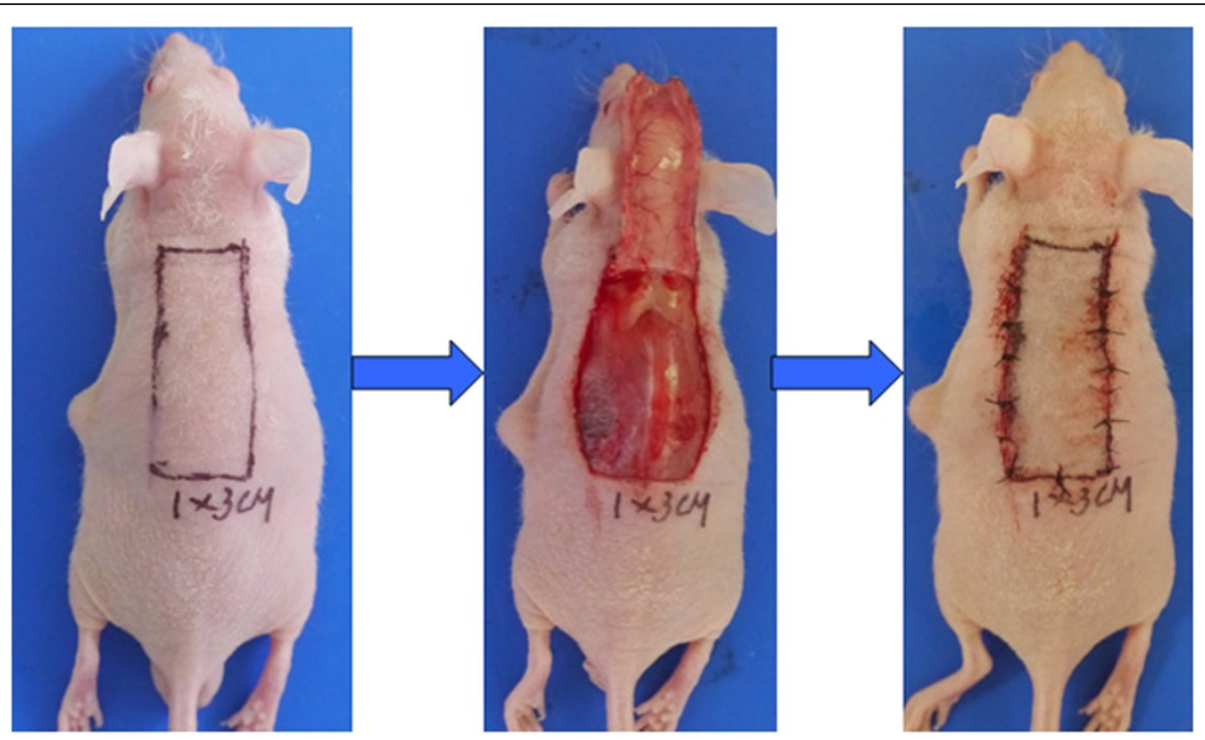

Figure 1 The reproducible mouse ischemic flap model was implemented using flaps that were $3 \mathrm{~cm}$ in length and $1 \mathrm{~cm}$ in width, with the main vessels coagulated by cautery. 
of control epithelial cells declined after $72 \mathrm{~h}$ of treatment with $\mathrm{CoCl}_{2}$, whereas epithelial cells pretreated with TSA showed higher viability (Figure 2A). A CCK-8 assay showed enhanced proliferation of TSA-pretreated cells after $\mathrm{CoCl}_{2}$ treatment compared with control cells $(0.74 \pm 0.02$ vs. $1.01 \pm 0.31, P=0.0313$; Figure $2 B)$. Using a Trypan Blue Assay, we determined the exact proportion of viable epithelial cells after treatment with $\mathrm{CoCl}_{2}$ and found that the survival rate of TSA-pretreated epithelial cells was higher than that of control cells after treatment with $\mathrm{CoCl}_{2}(49.33 \pm 7.29 \%$ vs. $73.17 \pm 6.05 \%, \mathrm{P}=0.0355$; Figure $2 \mathrm{C}$ ).

\section{Epithelial skin cells showed upregulated Wnt signaling} and increased expression of stem cell-related biomarkers after TSA pretreatment

The Wnt signaling pathway is characterized by the expression of several biomarkers, such as GSK-3 $\beta$ and $\beta$-catenin, which are regarded as being critical for stem cell regulation. qRT-PCR revealed an upregulation of $\beta$-catenin $(0.0048 \pm 0.0005$ vs. $0.0200 \pm 0.0037$, $\mathrm{P}=0.014)$ and a downregulation of GSK-3 $\beta(0.0273 \pm$ 0.0018 vs. $0.0117 \pm 0.0012, \mathrm{P}=0.012)$ in TSA-pretreated epithelial cells compared with control cells (Figure 3A). The expression of stem cell markers SOX2 (0.0029 \pm
0.0003 vs. $0.0051 \pm 0.0004, P=0.032)$, Nanog $(0.0002 \pm$ 0.0001 vs. $0.0046 \pm 0.0005, \mathrm{P}=0.001)$, and OCT4 $(0.0027 \pm$ 0.0008 vs. $0.0375 \pm 0.0045, \mathrm{P}=0.002$ ) was higher in TSApretreated cells than in control cells. Furthermore, the expression of VEGF $(0.0094 \pm 0.0007$ vs. $0.0276 \pm 0.0018$, $\mathrm{P}=0.006)$ was higher in TSA-pretreated cells than in control cells. Similar results were found using western blot analysis (Figure 3B).

\section{TSA pretreatment reduced flap necrosis in an ischemic flap model}

Pretreatment with TSA (10 mg/kg/d) enhanced tissue resistance to hypoxia and increased tissue survival area in an ischemic flap model (Figure 4A). That is, on the first day after surgery, there was no significant difference between TSA pretreatment and control groups in the area of surviving tissue $(96.34 \pm 2.19 \%$ vs. $98.56 \pm 1.69 \%, \mathrm{P}=$ 0.183 ; Figure $4 \mathrm{~B})$. On the third day, however, the ischemic flaps in the control group began to undergo necrosis, whereas the flaps in the TSA pretreatment group showed an enhanced resistance to hypoxia as evidenced by a greater tissue survival area $(73.72 \pm 6.09 \%$ vs. $89.82 \pm$ $7.48 \%, \mathrm{P}=0.043)$. On the fifth day after surgery, flap necrosis in TSA-pretreated mice advanced more slowly than control mice $(58.14 \pm 8.67 \%$ vs. $75.54 \pm 6.20 \%, \mathrm{P}=0.047)$.

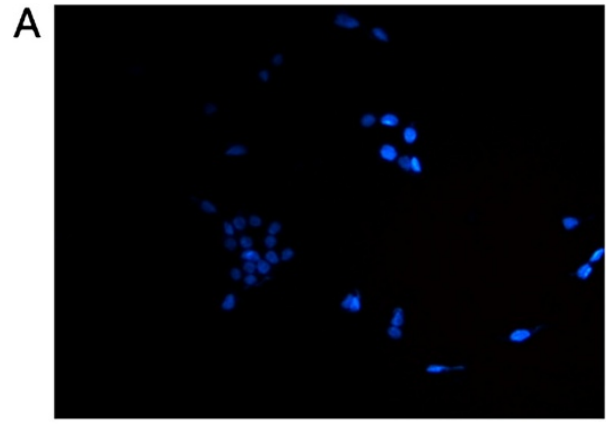

B

$\mathrm{Con}+\mathrm{Cocl} 2$

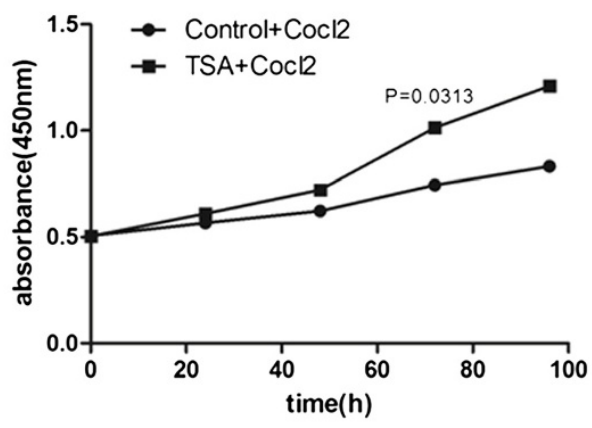

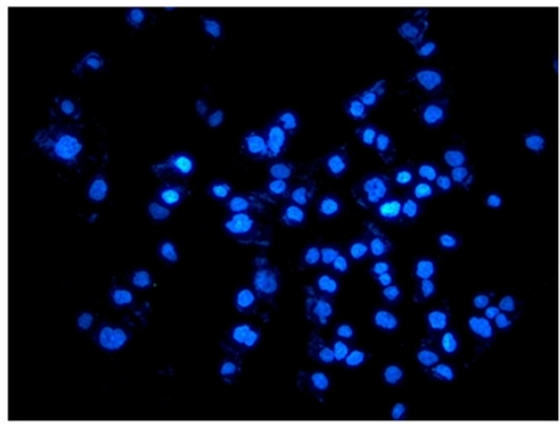

C $\mathrm{TSA}+\mathrm{Cocl} 2$

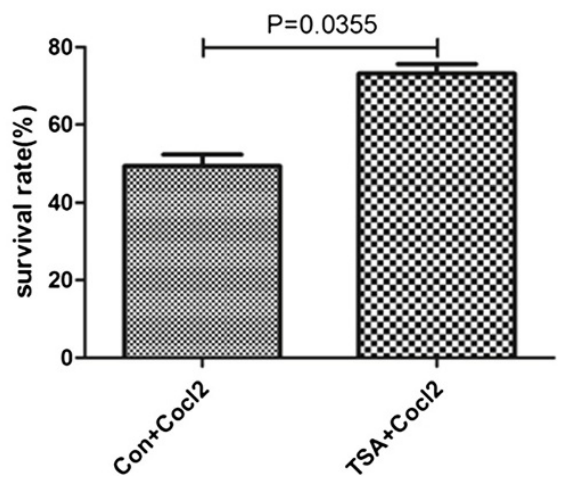

Figure 2 Isolated epidermal cells that were pretreated with TSA for 2 weeks showed enhanced resistance to $\mathrm{CoCl}_{2}$, which was used to mimic hypoxia in vitro. After exposure to $\mathrm{CoCl}_{2}$ for $72 \mathrm{~h}$, nuclear DAPI staining revealed larger number of TSA-pretreated cells than control cells (A). A CCK-8 assay demonstrated that TSA-pretreated cells showed more proliferation than control cells after exposure to $\mathrm{CgCl}_{2}$ for $96 \mathrm{~h}$ (B). A Trypan Blue assay showed that the survival rate of TSA-pretreated cells was higher than that of control cells after treatment with $\mathbf{C o C I _ { 2 }}$ ( $\mathbf{C}$ ). 


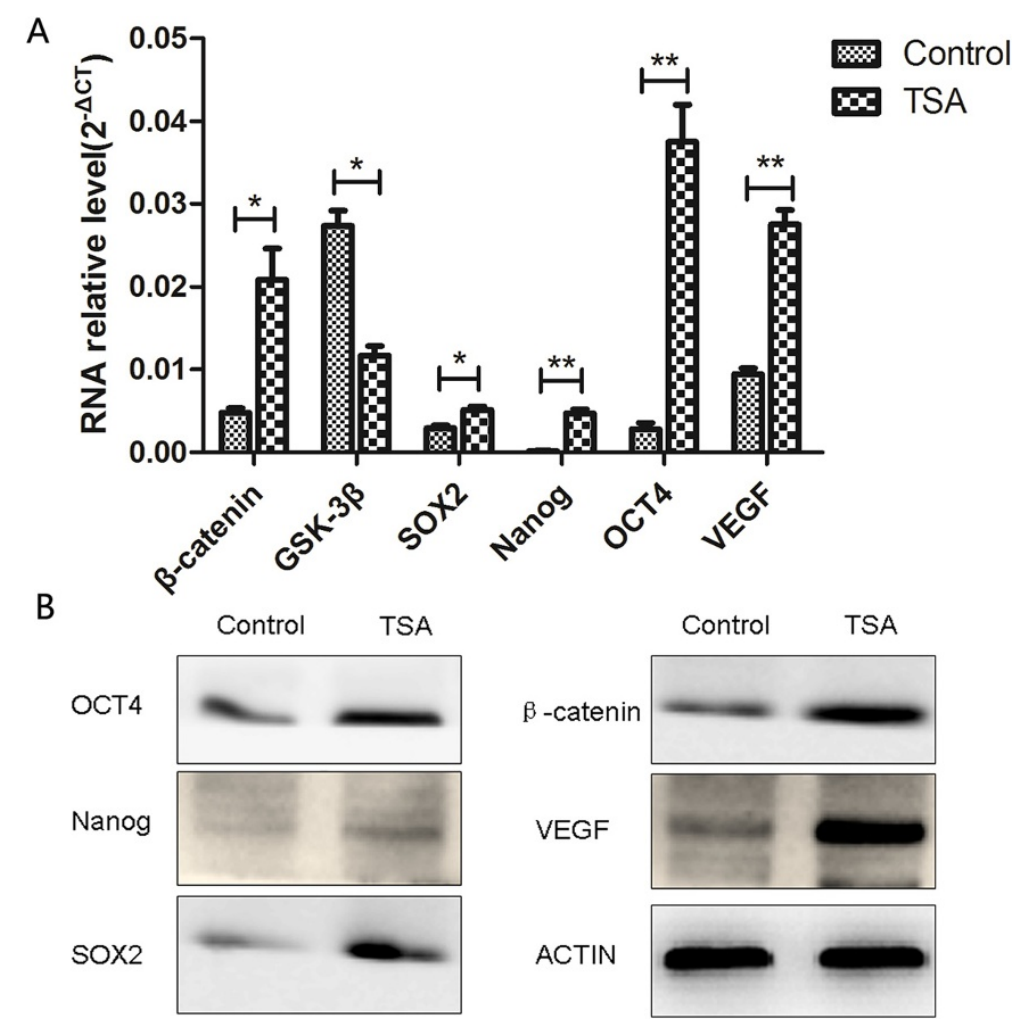

Figure 3 Epidermal cells showed upregulated Wnt signaling and enhanced stemness after pretreatment with TSA. qRT-PCR showed upregulation of $\beta$-catenin, SOX2, Nanog, OCT4, and VEGF and downregulation of GSK-3 $\beta$ in TSA-pretreated epithelial cells compared with control cells (A). Similar results were obtained using western blot analysis (B).

Finally, on the seventh day, flaps in TSA-pretreated mice showed a greater survival area than control mice (35.91 \pm $10.22 \%$ vs. $68.02 \pm 8.89 \%, P=0.016$ ).

TSA treatment upregulated Wnt signaling and increased the expression of stem cell-related markers in epithelial skin tissue

To investigate the mechanism by which TSA protects against ischemia-induced flap necrosis, we examined components of the Wnt signaling pathway and stem cell-related biomarkers in epithelial skin tissue using immunohistochemistry. We observed increased expression of $\beta$-catenin and decreased expression of GSK-3 $\beta$ after TSA pretreatment (Figure 5). Stem cell-related biomarkers such as SOX2 and OCT4 were also upregulated after TSA pretreatment. Furthermore, the expression of VEGF, which is involved in the regeneration of blood vessels, and CD34, which is a marker of microvessel density, were also upregulated in epithelial skin tissue after pretreatment with TSA.

\section{Discussion}

The human skin forms a large and important physical barrier between the body and its environment. In plastic surgery, tissue defects resulting from trauma, ablative surgery, or congenital malformation are frequently encountered, therefore flap transplantation is routinely used for re-establishing the epithelial barrier after injury. However, delayed healing or necrosis sometimes occurs when a free flap is transplanted from one area to another, which can increase the risk of infection and scar tissue formation or even lead to patient morbidity. Therefore, it is important for surgeons, who perform flap surgery, to have more knowledge of flap necrosis and how it can be prevented.

Ischemia is a condition of inadequate blood flow to a specific tissue area, which can lead to tissue hypoxia [11]. When the period of hypoxia exceeds the tolerance of transplanted free flap tissue, necrosis will occur. Whereas common epithelial skin cells show poor survivability of hypoxia, epithelial stem cells show a powerful resistance to maladaptive microenvironments [37]. In most organ systems, stem cells are thought to be the source of undifferentiated cells needed to maintain tissue homeostasis and to repair injury. One of the critical signaling pathways that regulates stem cell properties and plays an important role in skin organogenesis and regeneration is Wnt signaling, with several studies showing that Wnt signaling plays a critical role in tissue injury repair [21-23]. Phase I/II clinical trials demonstrate that 


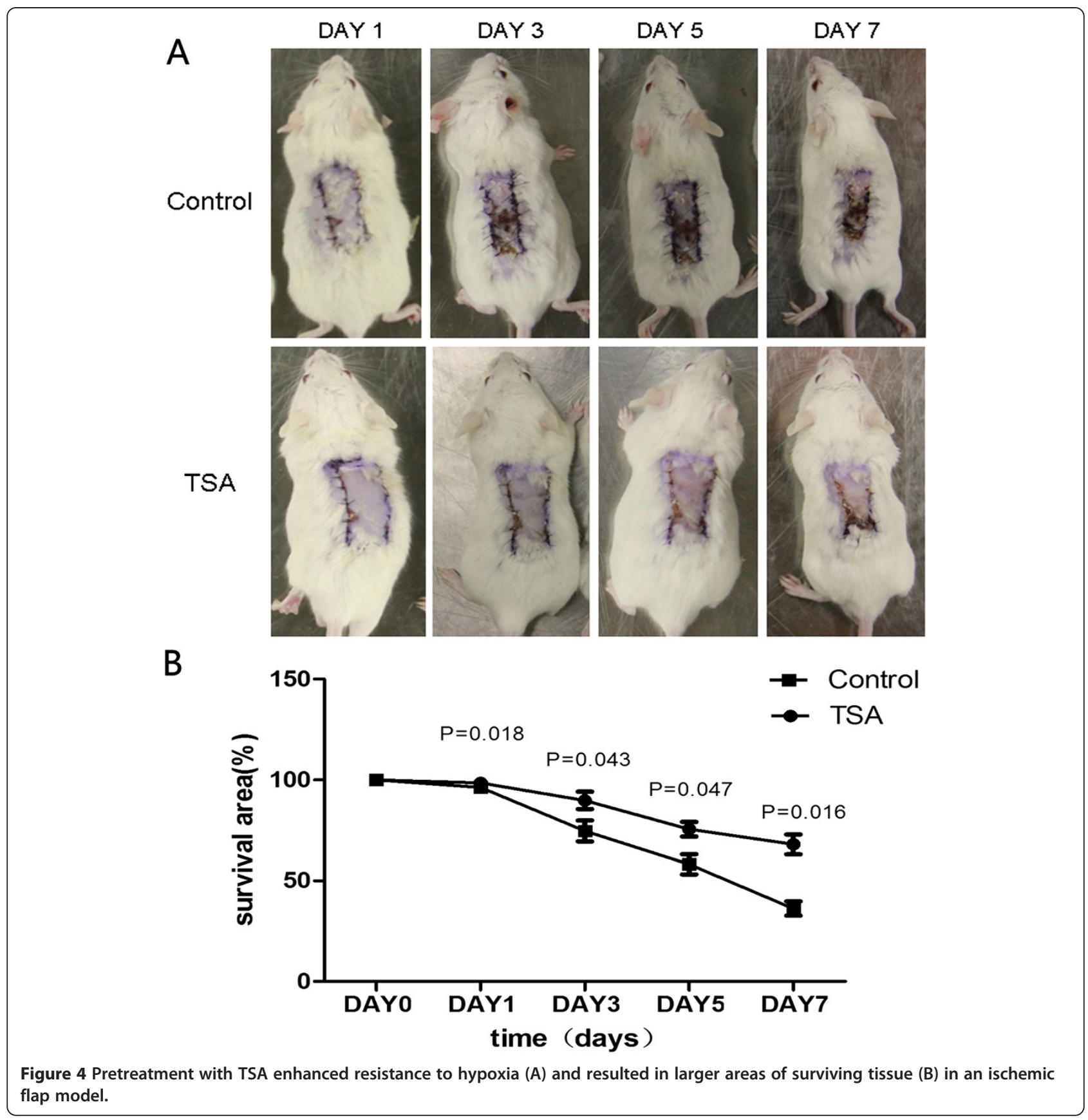

enhancing Wnt signaling via antibody-mediated repression of Dkk1 is an effective means of stimulating new bone formation [38]. Also, in states of debilitating chronic injury, transiently elevating Wnt signaling is beneficial for tissue regeneration [39]. In the present experiment, we found that isolated epidermal cells that were pretreated with TSA showed upregulated Wnt signaling and enhanced resistance to hypoxia in vitro. We also found less necrosis and upregulated Wnt signaling in flap tissue after TSA pretreatment in vivo. Thus, although endogenous Wnt signaling is a prerequisite for tissue repair, there are obvious caveats to this general conclusion because of limited Wnt signaling activation in epithelial histiocytes $[23,40,41]$. Therefore, finding an effective and convenient way to pre-generate a sufficient amount of Wnt signaling activation may be important for injury restoration in hypoxic flaps.

Traditional Chinese medicine, a type of alternative and complementary medicine, is commonly used in Asian countries to treat cancer as well as cardiovascular, cerebrovascular, metabolic, and neurodegenerative diseases. TSA, which is isolated from Danshen (Salvia miltiorrhiza), has 


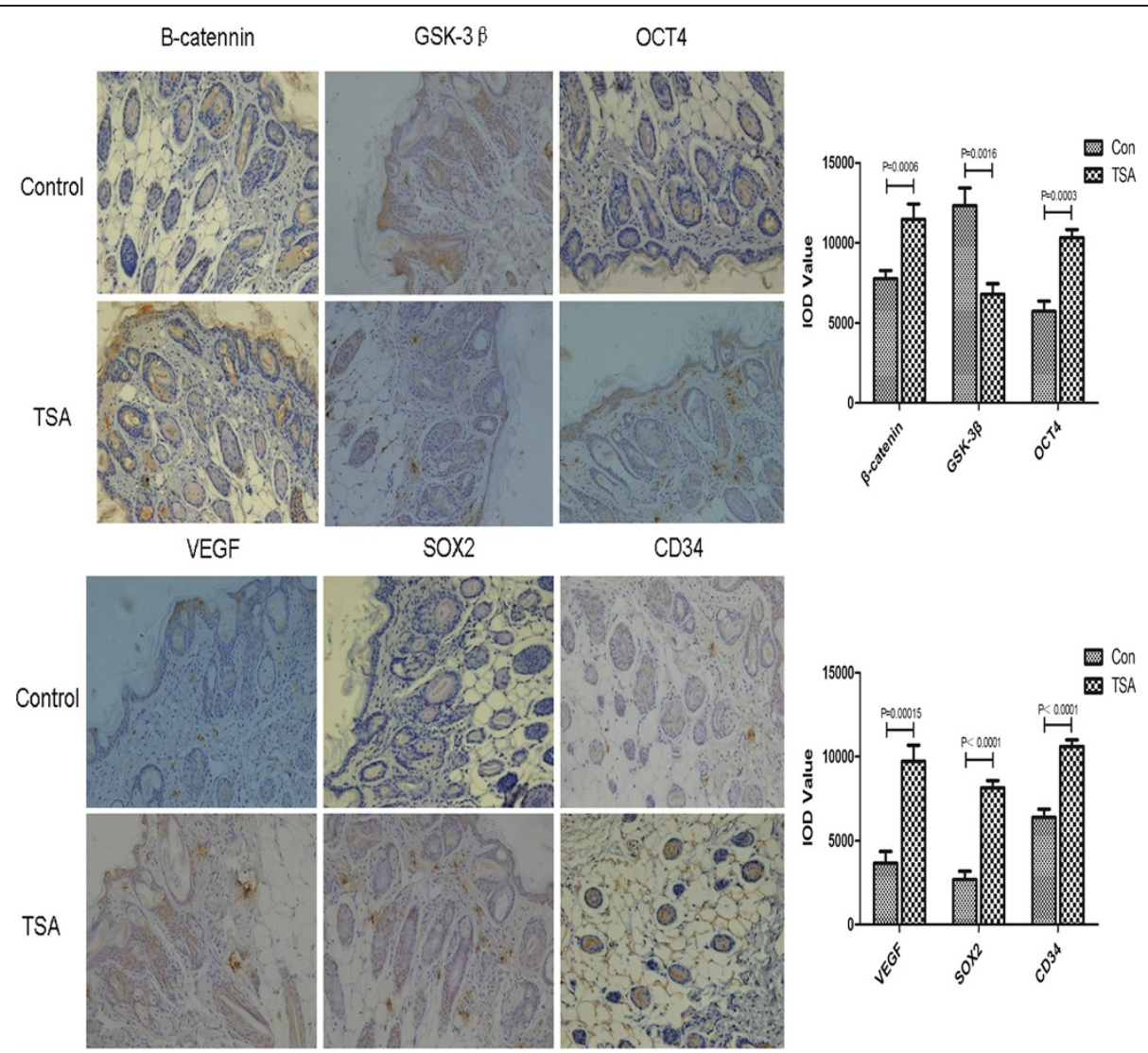

Figure 5 TSA pretreatment upregulated Wnt signaling and increased the expression of stem cell-related markers in mouse epithelial skin tissue.

multiple targets including transcription factors, scavenger receptors, ion channels, kinases, pro- and anti-apoptotic proteins, growth factors, inflammatory mediators, and microRNA [42]. For instance, Tang et al. showed that the neuroprotective role of TSA monotherapy is mediated by the PI3K/AKT signaling pathway [43]. Chen et al. found that TSA alleviates the proinflammatory responses associated with I/R-induced injury by downregulating MIF expression [24]. In addition, Zhang et al. showed that TSA enhances cell resistance to hypoxic insult by upregulating miR-133 expression through activation of MAPK-ERK $1 / 2$ [31]. In the present study, we found that epithelial skin cells, pretreated with, TSA showed greater viability than control cells after $\mathrm{CoCl}_{2}$ treatment in vitro. We also found that pretreatment with TSA enhanced tissue resistance to hypoxia and resulted in larger areas of surviving tissue in an in vivo ischemic flap model. Furthermore, we demonstrated that activation of the Wnt signaling pathway with the increased expression of $\beta$-catenin and down-regulation of GSK-3 $\beta$. The increased expression of stem cell-related markers such as SOX2, OCT4, and Nanog were also involved in the effect of TSA on epithelial cells and tissue with the activation of the Wnt signaling pathway. As to VEGF which is the base of angiogenesis was also up- regulated involve in the effect of TSA. So, we also found the increased expression CD34 after treated by TSA. And all of these stem cell- and angiogenesis -related markers determined the survival of flap during the process of ischemia and hypoxia after injury.

In summary, we provide experimental evidence that TSA pretreatment protects against necrosis of transplanted flap tissue in mice, suggesting that TSA pretreatment might be a potential way to improve the success of free flap surgery in humans. However, several fundamental questions remain concerning the ability of TSA to increase the stemness of epithelial skin cells. Therefore, additional animal models of ischemia should be utilized to further investigate the relationship between TSA and stemness, and future studies could also determine whether TSA can be clinically useful for treating human ischemic tissues and organs.

\section{Conclusions}

TSA pretreatment protects free flaps against hypoxic injury and increases the area of surviving tissue in transplanted flaps by activating Wnt signaling and upregulating stem cell-related biomarkers in epithelial skin cells. 


\section{Abbreviations}

TSA: Tanshinone II-A; I/R: Ischemia/reperfusion; MIF: Macrophage migration inhibitory factor; DAPI: 4'-6-Diamidino-2-phenylindole; $\mathrm{CoCl}_{2}$ : Cobalt chloride VEGF: Vascular endothelial growth factor; SOX2: Sex determining region Y-box 2; CCK-8: Cell Counting Kit-8; GSK-3ß: Glycogen synthase kinase-3 beta; MAPK: Mitogen-activated protein kinase; ERK: Extracellular signal-related kinase; PBS: Phosphate-buffered saline; DMEM: Dulbecco's Modified Eagle's Medium; DAPI: 4'-6-Diamidino-2-phenylindole; qRT-PCR: Quantitative real-time polymerase chain reaction.

\section{Competing interests}

The authors declare that they have no competing interests.

\section{Authors' contributions}

ZHX, LJW, YWS, YDG, GPQ, SZM, RHF, BFW, WJG, and ZXZ contributed to study design, analysis, and interpretation of data. ZXZ conceived of the study. ZHX and LJW performed the experiments. YWS, GPQ, SZM, and RHF participated in the isolation of primary epithelial cells. WJG participated in statistical analysis. ZHX drafted the manuscript. ZXZ carried out the revision and provided important suggestions. All authors approved the final manuscript.

\section{Acknowledgments}

This research project was supported by grants from the Shaanxi Science and Technology Development Plan Project (No. $2011 \mathrm{kjxx}$-26). The funders had no role in study design, data collection and analysis, decision to publish, or preparation of the manuscript.

\section{Author details}

${ }^{1}$ Department of Burns and Plastic Surgery, Shaanxi Provincial People's Hospital, 256 West Youyi Road, Xi'an 710068, China. ${ }^{2}$ Department of Plastic Surgery, The Second Affiliated Hospital of Soochow University, Suzhou 215004, China.

Received: 19 December 2013 Accepted: 27 August 2014

Published: 4 September 2014

\section{References}

1. Nahabedian MY, Momen B, Manson PN: Factors associated with anastomotic failure after microvascular reconstruction of the breast. Plast Reconstr Surg 2004, 114(1):74-82.

2. Wei FC, Celik N, Chen HC, Cheng MH, Huang WC: Combined anterolateral thigh flap and vascularized fibula osteoseptocutaneous flap in reconstruction of extensive composite mandibular defects. Plast Reconstr Surg 2002, 109(1):45-52.

3. Yoshikawa T, Mitsuno H, Nonaka I, Sen Y, Kawanishi K, Inada Y, Takakura Y, Okuchi K, Nonomura A: Wound therapy by marrow mesenchymal cell transplantation. Plast Reconstr Surg 2008, 121(3):860-877.

4. Li H, Zan T, Li Y, Weng R, Yang M, Du Z, Zhong S, Li Q: Transplantation of adipose-derived stem cells promotes formation of prefabricated flap in a rat model. Tohoku J Exp Med 2010, 222(2):131-140.

5. Yi CG, Xia W, Zhang LX, Zhen Y, Shu MG, Han Y, Guo SZ: VEGF gene therapy for the survival of transplanted fat tissue in nude mice. J Plast Reconstr Aesthet Surg 2007, 60(3):272-278.

6. Thom SR: Hyperbaric oxygen: its mechanisms and efficacy. Plast Reconstr Surg 2011, 127(Suppl 1):131S-141S.

7. Dennog C, Gedik C, Wood S, Speit G: Analysis of oxidative DNA damage and HPRT mutations in humans after hyperbaric oxygen treatment. Mutat Res 1999, 431(2):351-359.

8. Plafki C, Peters P, Almeling M, Welslau W, Busch R: Complications and side effects of hyperbaric oxygen therapy. Aviat Space Environ Med 2000, 71(2):119-124

9. Reichenberger MA, Heimer S, Schaefer A, Lass U, Gebhard MM, Germann G, Leimer U, Kollensperger $\mathrm{E}$, Mueller W: Adipose derived stem cells protect skin flaps against ischemia-reperfusion injury. Stem Cell Rev 2012, 8(3):854-862.

10. Aberdam D, Candi $E$, Knight RA, Melino G: miRNAs, 'stemness' and skin Trends Biochem Sci 2008, 33(12):583-591.

11. Wang WZ: Investigation of reperfusion injury and ischemic preconditioning in microsurgery. Microsurgery 2009, 29(1):72-79.

12. Nguyen $H$, Rendl M, Fuchs E: Tcf3 governs stem cell features and represses cell fate determination in skin. Cell 2006, 127(1):171-183.
13. Clayton E, Doupe DP, Klein AM, Winton DJ, Simons BD, Jones PH: A single type of progenitor cell maintains normal epidermis. Nature 2007, 446(7132):185-189.

14. Potten CS, Booth C: Keratinocyte stem cells: a commentary. J Invest Dermatol 2002, 119(4):888-899.

15. Willert K, Brown JD, Danenberg E, Duncan AW, Weissman IL, Reya T, Yates JR 3rd, Nusse R: Wnt proteins are lipid-modified and can act as stem cell growth factors. Nature 2003, 423(6938):448-452.

16. Reis $M$, Liebner S: Wnt signaling in the vasculature. Exp Cell Res 2013, 319(9):1317-1323.

17. Yu J, Vodyanik MA, Smuga-Otto K, Antosiewicz-Bourget J, Frane JL, Tian S, Nie J, Jonsdottir GA, Ruotti V, Stewart R, Slukvin II, Thomson JA: Induced pluripotent stem cell lines derived from human somatic cells. Science 2007, 318(5858):1917-1920.

18. Takahashi K, Tanabe K, Ohnuki M, Narita M, Ichisaka T, Tomoda K, Yamanaka S: Induction of pluripotent stem cells from adult human fibroblasts by defined factors. Cell 2007, 131(5):861-872

19. Gurley KA, Rink JC, Sanchez Alvarado A: Beta-catenin defines head versus tail identity during planarian regeneration and homeostasis. Science 2008, 319(5861):323-327

20. Petersen CP, Reddien PW: A wound-induced Wnt expression program controls planarian regeneration polarity. Proc Natl Acad Sci U S A 2009, 106(40):17061-17066.

21. Ramachandran R, Zhao XF, Goldman D: Ascl1a/Dkk/beta-catenin signaling pathway is necessary and glycogen synthase kinase-3beta inhibition is sufficient for zebrafish retina regeneration. Proc Natl Acad Sci U S A 2011, 108(38):15858-15863.

22. Ito M, Yang Z, Andl T, Cui C, Kim N, Millar SE, Cotsarelis G: Wnt-dependent de novo hair follicle regeneration in adult mouse skin after wounding. Nature 2007, 447(7142):316-320.

23. Whyte JL, Smith AA, Helms JA: Wnt signaling and injury repair. Cold Spring Harb Perspect Biol 2012, 4(8):a008078.

24. Chen Y, Wu X, Yu S, Lin X, Wu J, Li L, Zhao J, Zhao Y: Neuroprotection of tanshinone IIA against cerebral ischemia/reperfusion injury through inhibition of macrophage migration inhibitory factor in rats. PLOS One 2012, 7(6):e40165.

25. Gao S, Liu Z, Li H, Little PJ, Liu P, Xu S: Cardiovascular actions and therapeutic potential of tanshinone IIA. Atherosclerosis 2012, 220(1):3-10.

26. Tang F, Wu X, Wang T, Wang P, Li R, Zhang H, Gao J, Chen S, Bao L, Huang H, Liu P: Tanshinone II A attenuates atherosclerotic calcification in rat model by inhibition of oxidative stress. Vascul Pharmacol 2007, 46(6):427-438.

27. Xu S, Liu Z, Huang Y, Le K, Tang F, Huang H, Ogura S, Little PJ, Shen X, Liu P: Tanshinone II-A inhibits oxidized LDL-induced LOX-1 expression in macrophages by reducing intracellular superoxide radical generation and NF-kappaB activation. Trans/ Res 2012, 160(2):114-124

28. Fang J, Xu SW, Wang P, Tang FT, Zhou SG, Gao J, Chen JW, Huang HQ, Liu PQ: Tanshinone II-A attenuates cardiac fibrosis and modulates collagen metabolism in rats with renovascular hypertension. Phytomedicine 2010, 18(1):58-64.

29. Fu J, Huang H, Liu J, Pi R, Chen J, Liu P: Tanshinone IIA protects cardiac myocytes against oxidative stress-triggered damage and apoptosis. Eur J Pharmacol 2007, 568(1-3):213-221.

30. Park OK, Choi JH, Park JH, Kim IH, Yan BC, Ahn JH, Kwon SH, Lee JC, Kim YS, Kim M, Kang IJ, Kim JD, Lee YL, Won MH: Comparison of neuroprotective effects of five major lipophilic diterpenoids from Danshen extract against experimentally induced transient cerebral ischemic damage. Fitoterapia 2012, 83(8):1666-1674.

31. Zhang L, Wu Y, Li Y, Xu C, Li X, Zhu D, Zhang Y, Xing S, Wang H, Zhang Z, Shan H: Tanshinone IIA improves miR-133 expression through MAPK ERK1/2 pathway in hypoxic cardiac myocytes. Cell Physiol Biochem 2012, 30(4):843-852

32. Zhu B, Zhai $Q$, Yu B: Tanshinone IIA protects rat primary hepatocytes against carbon tetrachloride toxicity via inhibiting mitochondria permeability transition. Pharm Biol 2010, 48(5):484-487.

33. Fusenig NE, Worst PK: Mouse epidermal cell cultures. I isolation and cultivation of epidermal cells from adult mouse skin. J Invest Dermatol 1974, 63(2):187-193.

34. Macfarlan TS, Gifford WD, Driscoll S, Lettieri K, Rowe HM, Bonanomi D, Firth A, Singer O, Trono D, Pfaff SL: Embryonic stem cell potency fluctuates with endogenous retrovirus activity. Nature 2012, 487(7405):57-63. 
35. Weng R, Li Q, Li H, Yang M, Sheng L: Mimic hypoxia improves angiogenesis in ischaemic random flaps. J Plast Reconstr Aesthet Surg 2010, 63(12):2152-2159.

36. Gao Q, Qiu SJ, Fan J, Zhou J, Wang XY, Xiao YS, Xu Y, Li YW, Tang ZY: Intratumoral balance of regulatory and cytotoxic $T$ cells is associated with prognosis of hepatocellular carcinoma after resection. J Clin Oncol 2007, 25(18):2586-2593.

37. Alonso L, Fuchs E: Stem cells of the skin epithelium. Proc Natl Acad Sci U S A 2003, 100(Suppl 1):11830-11835.

38. Fulciniti M, Tassone P, Hideshima T, Vallet S, Nanjappa P, Ettenberg SA, Shen Z, Patel N, Tai YT, Chauhan D, Mitsiades C, Prabhala R, Raje N, Anderson KC, Stover DR, Munshi NC: Anti-DKK1 mAb (BHQ880) as a potential therapeutic agent for multiple myeloma. Blood 2009, 114(2):371-379.

39. Anderson EC, Wong MH: Caught in the Akt: regulation of Wnt signaling in the intestine. Gastroenterology 2010, 139(3):718-722.

40. Agholme F, Aspenberg P: Wnt signaling and orthopedics, an overview. Acta Orthop 2011, 82(2):125-130.

41. Hermans KC, Daskalopoulos EP, Blankesteijn WM: Interventions in Wnt signaling as a novel therapeutic approach to improve myocardial infarct healing. Fibrogenesis Tissue Repair 2012, 5(1):16.

42. Xu S, Liu P: Tanshinone II-A: new perspectives for old remedies. Expert Opin Ther Pat 2013, 23(2):149-153.

43. Tang Q, Han R, Xiao H, Shen J, Luo Q, Li J: Neuroprotective effects of tanshinone IIA and/or tetramethylpyrazine in cerebral ischemic injury in vivo and in vitro. Brain Res 2012, 1488:81-91.

doi:10.1186/1472-6882-14-331

Cite this article as: Xu et al:: Tanshinone IIA pretreatment protects free flaps against hypoxic injury by upregulating stem cell-related biomarkers in epithelial skin cells. BMC Complementary and Alternative Medicine 2014 14:331

\section{Submit your next manuscript to BioMed Central and take full advantage of:}

- Convenient online submission

- Thorough peer review

- No space constraints or color figure charges

- Immediate publication on acceptance

- Inclusion in PubMed, CAS, Scopus and Google Scholar

- Research which is freely available for redistribution 